\title{
A tribute to our heroes and thoughts about collaborative relationships
}

\author{
Maria Petrescu ${ }^{1}$ Anjala S. Krishen ${ }^{2}$
}

Accepted: 28 April 2021 / Published online: 12 May 2021

(c) The Author(s), under exclusive licence to Springer Nature Limited 2021

If nothing else, the pandemic taught society to value human connections and social networks. As editors, we have relied heavily on researchers, academics, and practitioners to send creative work to Journal of Marketing Analytics. In this editorial, we want to thank and honor all authors, reviewers, and publishers for their great efforts in 2020 and mention the editorial awards for last year:

- Best paper of the year: "Protecting survey data on a consumer level", Schneider and Iacobucci (2020);

- Most popular paper of the year: "Cutoff criteria for overall model fit indexes in generalized structured component analysis", Cho et al. (2020);

- Best paper in a special issue: "The impact of mobile customer relationship management ( $m C R M)$ on sales collaboration and sales performance", Rodriguez and Boyer (2020).

The publication process requires more than creative content, and relies heavily on the dedication of many "behind the scenes" heroes who perform gratis service to the academy for the purpose of building the knowledgebase of the world. As such, we also want to thank the editor of our special issue on Analytics in Sales, Dr. Ricky Fergurson, and all our reviewers who worked extremely hard in 2020, including our best reviewers Dr. John Gironda and Sheen Kachen.

After studying the papers selected by our editorial team as the best for 2020, checking downloads and reading analytics, we noticed an increase in popularity towards quantitative, applied studies that can easily be transposed and relevant

Anjala S. Krishen

anjala.krishen@unlv.edu

Maria Petrescu

mpetrescu@monaco.edu

1 Inseec U. Research Center, International University of Monaco, Monaco, Monaco

2 Lee Business School, University of Nevada, Las Vegas, Las Vegas, NV, USA to both analytics research and practice. This again teaches us the importance of good relationships among researchers, academics, and practitioners in the development of the marketing analytics field.

Previous researchers have already noted the need for collaborative relationships between marketing research and practice to ensure research rigor to advance the field and gain practitioner audiences (Gauri and Grewal 2021; Iacobucci et al. 2019; Petrescu and Krishen 2017). Collaborative partnerships can be vital for the development of the field of analytics too, especially considering the fast and dynamic development of new technologies and methods of data management based on artificial intelligence (Grewal et al. 2021; Roggeveen and Sethuraman 2020).

Considering the importance of rigor, relevance, timeliness, and usefulness in our marketing research, we want to encourage a more thorough and systematic view of the practice of marketing analytics, management of big data, and use of artificial intelligence in analytics (Bolton 2019; Dekimpe and Geyskens 2019; Gauri and Grewal 2021). For this, we invite both researcher and practitioner commentaries on cutting-edge technologies and data management methods, as well as reviews of software options and books that propel our field forward. We also encourage collaborative teams of researchers and practitioners to submit proposals of special issues on key contemporary topics in the field of marketing analytics.

\section{References}

Bolton, R. 2019. Responsible Research in Retailing: Is Your Research Useful? Journal of Retailing 95 (3): 3-8.

Cho, G., H. Hwang, M. Sarstedt, and C. Ringle. 2020. Cutoff Criteria for Overall Model Fit Indexes in Generalized Structured Component Analysis. Journal of Marketing Analytics 8: 189-202. https:// doi.org/10.1057/s41270-020-00089-1.

Dekimpe, M.G., and Inge Geyskens. 2019. Retailing Research in Rapidly Changing Times: On the Danger of Being Leapfrogged by Practice. Journal of Retailing 95 (1): 6-9. 
Gauri, D.K., and D. Grewal. 2021. Navigating the Retailing Frontier through Academic and Practitioner Collaboration. Journal of Retailing 97 (1): 2-5. https://doi.org/10.1016/j.jretai.2021.02.005.

Grewal, Dhruv, Dinesh Gauri, Anne L. Roggeveen, and Raj Sethuraman. 2021. Strategizing Retailing in the New Technology Era. Journal of Retailing 97 (1): 6-12.

Iacobucci, D., M. Petrescu, A. Krishen, and M. Bendixen. 2019. The State of Marketing Analytics in Research and Practice. Journal of Marketing Analytics 7 (3): 152-181. https://doi.org/10.1057/ s41270-019-00059-2.

Petrescu, M., and A.S. Krishen. 2017. Marketing Analytics: From Practice to Academia. Journal of Marketing Analytics 5 (1): 45-46.

Rodriguez, M., and S. Boyer. 2020. The Impact of Mobile Customer Relationship Management (mCRM) on Sales Collaboration and Sales Performance. Journal of Marketing Analytics 8: 137-148. https://doi.org/10.1057/s41270-020-00087-3.

Roggeveen, A.L., and R. Sethuraman. 2020. Customer-Interfacing Retail Technologies in 2020 \& Beyond: An Integrative Framework and Research Directions. Journal of Retailing 96 (3): 299309. https://doi.org/10.1016/j.jretai.2020.08.001.

Schneider, M.J., and D. Iacobucci. 2020. Protecting Survey Data on a Consumer Level. Journal of Marketing Analytics 8: 3-17. https:// doi.org/10.1057/s41270-020-00068-6.

Publisher's Note Springer Nature remains neutral with regard to jurisdictional claims in published maps and institutional affiliations.
Maria Petrescu is an Associate Professor of Marketing at International University of Monaco, Inseec U. Research Center. Her main research areas include marketing analytics and digital marketing. She has published articles in journals such as Psychology \& Marketing, the Journal of Marketing Management, Public Management Review, Journal of Product and Brand Management, the Journal of Retailing and Consumer Services, and the Journal of Internet Commerce.

Anjala S. Krishen is a Professor of Marketing and International Business and Director of MBA Programs at University of Nevada, Las Vegas, and has a B.S. in Electrical Engineering from Rice University, and an M.S. Marketing, MBA, and Ph.D. from Virginia Tech. She held management positions for 13 years before pursuing a doctorate. As of 2021, she has published over 65 peer-reviewed journal papers in highly ranked journals. In 2016, she gave a TEDx talk (at UNR) titled "Opposition: The light outside of the dark box," and a UNLV Creates speech entitled "Consuming to Creating, Watching to Doing, Seeing to Being." To date, she has completed over 65 marathons, seven ultramarathons, and five 100 milers, and has a black belt in Taekwondo. 